\title{
LA e-EXPERIENCIA DE MARCA A TRAVÉS DE LOS MEDIOS SOCIALES Y SU INFLUENCIA EN LA e-CALIDAD DE LA RELACIÓN Y LA e-FIDELIZACIÓN. ANÁLISIS EMPÍRICO EN LOS SITIOS WEB DE VIAJES
}

\author{
José Ramón Sarmiento Guede* \\ Universidad Rey Juan Carlos. Madrid \\ https://orcid.org/0000-0002-0342-0348 \\ António José Ferrão Filipe** \\ Universidade Portucalense. Porto. Portugal
}

\section{RESUMEN}

El objetivo principal de este artículo es verificar la relación de la experiencia web de marca a través de los sitios web organizacionales o de los medios sociales de viajes y constatar su influencia en la calidad de la relación electrónica y en la fidelización electrónica de los usuarios. Para confirmar las hipótesis, se utilizan técnicas cuantitativas de una muestra de 769 usuarios. Del modelo propuesto, podemos concluir que la experiencia de marca a través de los medios sociales de viajes es el predictor directo más importante de la calidad de la relación y de la fidelización de marca.

Palabras clave: Experiencia de marca; calidad de la relación; fidelización, medios sociales; sitios web de viajes.

The electronic brand experience through social media and its influence on the electronic relationship quality and electronic loyalty. Empirical analysis on travel websites

\section{ABSTRACT}

The main objective of this article is to verify the relationship of the brand web experience through the organizational websites or the social travel media and to verify its influence on

Fecha de recepción: 13 de marzo de 2018

Fecha de aceptación: 5 de noviembre de 2018

*Departamento de Economía de la Empresa. Área de Comercialización e Investigación de Mercados. Facultad de Ciencias Jurídicas y Sociales. Universidad Rey Juan Carlos Paseo de los Artilleros, s/n. 28032 MADRID (España).E-mail: joseramon.sarmiento@urjc.es

**Vicerrector de la Universidad Portucalense. R. Dr. António Bernardino de Almeida 541, 4200-072 PORTO (Portugal).E.-mail: ferraof@upt.pt 
the quality of the electronic relationship and the electronic loyalty of the users. To confirm the hypotheses, quantitative techniques were used in a sample of 769 users. From the proposed model, we can conclude that the brand experience through social travel media is the most important direct predictor of the quality of the relationship and brand loyalty.

Keywords: Brand experience; relationship quality; loyalty; social media; travel websites

\section{INTRODUCCIÓN}

El marketing de relaciones es un término cuyo significado abarca más que unos meros objetivos con sus estrategias; en consecuencia, resulta mejor entenderlo como un enfoque en lo que prima es el desarrollo de las relaciones con los clientes (Sarmiento, 2014). Este enfoque lo han estado aplicando en la práctica diaria los pequeños comerciantes desde siempre. Aunque carecían de la tecnología con la que ahora contamos, «los antiguos comerciantes, hoy conocidos como tenderos, al igual que las actuales empresas manejadas por sus mismos dueños, llevaban la relación con sus clientes más fieles de una manera tan personal que los conocían y mencionaban por su nombre, sabían de sus gustos, los trataban de forma que les satisficiera, logrando a cambio su lealtad (Sarmiento, 2015)».

Hoy en día el mercado es muy competitivo y la pérdida de clientes puede llegar a ser costosísima. Por ello, resulta tan rentable desarrollar una estrategia relacional basada en adquirir y retener clientes (Egan, 2011). Los tenderos ya no intentan solo satisfacer al cliente; actualmente, también buscan desarrollar relaciones con ellos. Pues, la idea de que las relaciones son más rentables que las propias satisfacciones es un hecho constatado durante los últimos años (Hess y Story, 2005; Chung y Shin, 2009; Egan, 2011).

La calidad de la relación aparece definida como «un constructo de orden superior compuesto por dimensiones diferentes, aunque relacionadas» (Roberts et al. 2003:190) o como «un constructo multidimensional formado por la confianza, la satisfacción y el compromiso, condicionados por la evaluación de la relación cliente». Estas dimensiones de la calidad de la relación (satisfacción, confianza y compromiso) se originan y se desarrollan a partir de encuentros discretos o de simples transacciones (Egan, 2011); sin embargo, alcanzar con éxito una relación de calidad dependerá en gran medida de las herramientas a disposición del marketing para llevar a esos consumidores hacia la formación de conexiones personales y funcionales (Hess y Story, 2005).

Al tiempo que evolucionaba el paradigma del marketing de relaciones, la revista económica TIME rompía el 2 de abril del 2005 con una tradición de casi 40 años, asignando la portada de la personalidad de 2006 al consumidor virtual en vez de a una persona concreta. Con ello, resaltaba la formación de una nueva clase de consumidor en cuya vida diaria Internet estaba cada vez más integrada. De esta forma, describía cómo un fenómeno denominado medios sociales estaba afectando a la forma en que el consumidor se comunicaba, tomaba decisiones, se socializaba, aprendía, se entretenía, interactuaba o hacía sus compras (Constantinides y Fountain, 2007). Además de haber transformado las actitudes 
y el comportamiento del consumidor (Solomon et al., 2012), también estaba trastocando las estructuras de poder del mercado, originando una migración sustancial desde los vendedores hacia los clientes y haciendo aparecer una nueva figura de consumidor activo denominada prosumidor (Toffler, 1980). La causa principal que explica esta migración de poder se debe a que los consumidores, gracias a Internet, a los medios sociales y a los smartphones, mediante un solo clic tienen un acceso ilimitado a la información y a la elección de cualquier producto o servicio en cualquier momento y en cualquier lugar.

En este trabajo de investigación, realizaremos un análisis comparativo del contenido corporativo generado por la empresa (sitios web corporativos de viajes) y del contenido generado por los usuarios a través de los medios sociales (medios sociales en los sitios web de viajes).

Los sitios web de viajes que se analizaron los hemos clasificado en sitios web de transporte, alojamiento, agencias de viajes, de destinos, de opinión y motores de búsqueda. Además, analizamos los medios sociales que disponen de estos sitios web de viajes y en el que los usuarios pueden generar contenido. Los medios sociales que podemos encontrar en estos sitios web de viajes y que se analizaron fueron las redes sociales, las redes sociales profesionales, los blogs, los microbloggins, los foros, los medios sociales de imágenes, los medios sociales de vídeos, los juegos virtuales, los mundos virtuales y los proyectos de colaboración (Sugimoto et al., 2017; Alalwan et al., 2017).

La elección de estas herramientas, sitios web corporativos y los medios sociales, está justificada por dos razones: (1) por la falta de artículos de investigación que realicen un análisis comparativo entre el contenido que generan los sitios corporativos de viajes y el contenido que generan los usuarios en los sitios web de viajes a través de los medios sociales, y (2) por la distinta forma de influir en el comportamiento del consumidor. El sitio web es una herramienta controlada por la organización, mientras que los medios sociales son herramientas ya controlables por los usuarios (Constantinides y Fountain, 2007; Kotler, 2013).

Contamos ya con investigaciones en las que se argumenta que la experiencia electrónica constituye un tema de capital importancia para el marketing (Constantinides, 2003; Egan, 2009); nosotros sostenemos que también lo es para el desarrollo de una actitud o comportamiento positivo hacia la marca. Porque no puede ser definida la experiencia web solo como la percepción total del consumo de una empresa en línea (Watchfire Whitepaper Series, 2000), sino también como el resultado de estar expuesta a una combinación de herramientas de marketing, en este caso, de los sitios web y de los medios sociales de empresas turísticas.

Hace pocos años, los clientes eran meros usuarios de los sitios web de viajes; ejercían un papel pasivo en su desarrollo. Concretamente, solo podían navegar y realizar transacciones electrónicas (comercio electrónico), pero no contribuían a desarrollar el servicio electrónico. Por el contrario, con la llegada de las aplicaciones web 2.0 y los Medios Sociales, la situación cambió radicalmente. Desde entonces, los usuarios pudieron crear, cargar o intercambiar contenidos o comunicarse con otros usuarios gracias a los distintos tipos de medios sociales (redes sociales, blogs, micro-blogging, sitios web de imágenes, sitios web de vídeos, foros, juegos virtuales, mundos virtuales, mensajería instantánea y redes sociales profesionales). Por tanto, en los sitios web 2.0 de viajes, los usuarios pasan 
a ser considerados como los actores de calidad y los críticos de hecho, dado que una experiencia electrónica mala puede afectar a la calidad de la relación y, consecuentemente, al comportamiento del usuario (Fassnacht y Koese, 2006).

Ante este contexto y habiendo revisado la literatura existente sobre el tema, formulamos las principales preguntas de investigación:

$\mathrm{Q}_{1}$ ¿Con qué herramienta se gestionan mejor las relaciones con los clientes, con los sitios web corporativos o con los medios sociales?

$\mathrm{Q}_{2}$ ¿Cómo influyen los sitios web corporativos de viajes en la calidad de la relación y en la fidelización?

$\mathrm{Q}_{3}$ ¿Cómo influyen los medios sociales de los sitios web de viajes en la calidad de la relación y en la fidelización?

Para dar antes respuesta a estas preguntas, estructuraremos nuestro trabajo de la siguiente manera; (1) primero, revisaremos la literatura sobre los conceptos que vamos a analizar en nuestro modelo de investigación, es decir, la experiencia de marca en los sitios web corporativos de viajes y en los medios sociales de viajes, además de la calidad de la relación y la fidelización; (2) en segundo lugar, relacionaremos todas la dimensiones de estudio y platearemos la hipótesis de investigación; (3) en tercer lugar, explicaremos la metodología utilizada para constatar las hipótesis mediante técnicas cuantitativas; (4) en cuarto lugar, presentaremos los resultados mediante un análisis de regresión lineal; (5) por último, expondremos las conclusiones que dan respuesta a las preguntas de investigación.

\section{MARCO TEÓRICO Y PLANTEAMIENTO DE LAS HIPÓTESIS}

Para responder a las preguntas de investigación anteriormente planteadas, idearemos un modelo de los antecedentes y los consecuentes de la calidad de la relación en los sitios web de viajes basándonos en algunos trabajos como los de Constantinides (2004), Cristóbal et al. (2007), Ho y Lee (2007), Chung y Shin (2010) y Moreira et al. (2017). Además, asumimos que, en entornos electrónicos, la experiencia de marca es un antecedente y la fidelización, un consecuente de la calidad de la relación como muy bien apuntó Athanasopoulou (2009).

\subsection{La e-Experiencia de marca como antecedente}

La experiencia de marca en entornos electrónicos fue llamando la atención de los académicos e investigadores de marketing a medida en que los consumidores iban buscando marcas que les brindaran experiencias únicas y personalizadas (Zarantonello y Schmitt, 2010). Moreira et al. (2017) afirman que el marketing transaccional apela a los vínculos funcionales con el cliente. Pero ahora los clientes buscan actividades más emocionales, y el marketing experiencial emerge como un buen punto de partida para la búsqueda de relaciones con los clientes.

Son escasas las definiciones de la experiencia de marca electrónicas, seguramente por su complejidad y por falta de estudios. Chaffey y Ellis-Chadwick (2012:370) definen 
la experiencia electrónica del usuario como «la combinación de factores relacionales y emocionales que utiliza una organización mediante servicios online para influir en la percepción de los usuarios sobre la marca». Partiendo de que el usuario en línea no es un simple comprador, sino también un usuario de la tecnología de la información (Cho y Park, 2001), podemos argumentar que la experiencia en línea es un tema más complejo que una mera transacción. Pues la percepción del usuario en línea está influida por el diseño, las emociones, el ambiente, la comunicación, la comunidad, la seguridad y por otras características web durante la interactividad con el ordenador, características, por lo demás, destinadas a influir en el resultado final de la interactividad en línea (Constantinides, 2004). Para Brakus et al. (2009:53), las experiencias de marca son «respuestas subjetivas del consumidor (sensaciones, sentimientos y cogniciones) y respuestas de comportamiento evocadas por estímulos relacionados con la marca que forman parte del diseño, la identidad, la información, las comunicaciones y el ambiente».

Numerosos autores afirman que las dimensiones de diseño, seguridad, información y comunicación que forman la experiencia electrónica influyen directamente en la calidad de la relación y en sus consecuentes, en este caso, la fidelidad de los clientes (Cristóbal et al., 2007; Ho y Lee, 2007; Park y Gretzel, 2007; Kim y Fesenmaier, 2008).

Así, de lo expuesto parece seguirse que las dimensiones que mejor definen la experiencia electrónica vienen determinadas en gran medida por la interfaz entre el usuario y la marca (Chung y Shin 2010), pues no hemos de olvidar que el entorno digital difiere del entorno analógico. Por lo tanto, siguiendo el mismo modelo de investigación de Constantinides (2004), Cristóbal et al. (2007), Ho y Lee (2007) Chung y Shin (2010) y Moreira et al. (2017), hemos identificado las siguientes dimensiones como las que mejor definen la experiencia de marca en entornos electrónicos; son estas: (1) el diseño, sustituto de la tienda física, puede llegar a tener un efecto positivo para realizar compras o buscar información (Liu y Arnett, 2000; Loiacono et al., 2000; Yoo y Donthu, 2001; Wolfinbarger y Gilly, 2001, 2002, 2003; Zeithaml et al., 2001; Cristóbal et al., 2007; Chung y Shin, 2010); (2) la seguridad, que salvaguarda las transacciones y la privacidad de los usuarios, dos de los factores más importantes de los sitios web y los medios sociales (Liu y Arnett, 2000; Loiacono et al., 2000; Yoo y Donthu, 2001; Wolfinbarger y Gilly, 2001, 2002, 2003; Zeithaml et al., 2001; Parasuraman et al., 2005; Chung y Shin, 2010); (3) la información: pues antes los usuarios eran sujetos pasivos que se dedicaban únicamente a realizar simples transacciones; ahora buscan también información sobre los productos o servicios de las distintas marcas (Liu y Arnett, 2000; Loiacono et al., 2000; Barnes y Vidgen, 2002; Chung y Shin, 2010); (4) la comunicación: últimamente, los usuarios tienden a construir comunidades online y a co-producir el servicio, por lo que es esencial que las marcas les faciliten herramientas interactivas para poder comunicarse (Loiacono et al., 2000; Barnes y Vidgen, 2002; Cox y Dale, 2001; Chung y Shin, 2010).

\subsection{La e-Calidad de la relación}

El concepto calidad de la relación nace de la teoría e investigación en el campo del marketing de relaciones para fortalecer las relaciones con los clientes y convertirlos en leales (Rauyruen y Miller, 2007). Por lo demás, es un concepto muy estudiado por autores 
como Ulaga y Eggert (2006), Chen et al. (2008), Holmlund (2008) Athanasopoulou (2008, 2009) y Moliner (2009) que conciben como un constructo de orden superior formado por varios componentes o dimensiones.

En esta investigación, después de haber revisado los trabajos realizados hasta ahora sobre la calidad de la relación electrónica (Athanasopoulou, 2008, 2009), podemos sostener que las dimensiones más repetidas, más utilizadas y que mejor definen dicho concepto son estas tres: (1) confianza; (2) satisfacción; y (3) compromiso (Athanasopoulou, 2009), tres dimensiones diferentes, aunque interrelacionadas.

La confianza electrónica está considerada como uno de los requisitos indispensables para el éxito del comercio electrónico (Chung y Shin, 2010). Como los entornos electrónicos se caracterizan por la incertidumbre, el anonimato, la falta de control y el oportunismo, es la confianza un elemento crucial en el entorno electrónico. Por consiguiente, si un sitio web o un medio social está diseñado de una manera segura, si respeta la privacidad y si facilita la navegación, repercutirá positivamente sobre la confianza electrónica (Corritorea et al., 2003). La confianza aparece definida como la creencia, la benevolencia y la integridad del proveedor de servicios (Mayer et al., 1995), o como la fiabilidad y la integridad (Morgan y Hunt, 1994) de un socio. De igual modo, el concepto puede aplicarse a los servicios electrónicos (McKnight et al., 2002). Así, para Gefen, Karahanna y Straub (2003), la confianza es como un conjunto de creencias específicas que afectan principalmente a la integridad (honestidad), la benevolencia (motivación para actuar para el interés común) y previsibilidad (coherencia conductual del administrador de servicios). Y, cuando los clientes confían en una marca, probablemente tendrán más intenciones de compra positivas hacia esa marca (Moreira y Silva, 2015).

Zeithmal et al. (2009) sentaron que Internet es un servicio, y Hwang y Kim (2007) ven el sitio web como un proveedor de servicios, de forma que la confianza hacia un sitio web o un medio social estará determinada por la percepción de la experiencia electrónica (Bliemel y Hassanein, 2007; Moreira et al., 2017). Así pues, la relación entre experiencia y confianza electrónicas es un hecho (Grönroos, 2015), ya que la confianza electrónica se basa en la credibilidad que les merece a los usuarios un sitio web o un medio social.

Autores como Karjaluoto et al. (2012) probaron que las emociones desarrolladas en un sitio web o en un medio social a través de la experiencia tienen un efecto positivo en la confianza y también demostraron que influían en la lealtad del cliente en la industria de las telecomunicaciones inalámbricas. Asimismo, Moreira et al. (2017) constataron que, en el contexto de la industria de juegos virtuales, la experiencia electrónica tiene un efecto positivo en la confianza electrónica.

Tras haber realizado una revisión de la literatura existente sobre la experiencia electrónica de marca y la confianza electrónica de marca (Grönroos, 2000; Athanasopoulou, 2008, 2009; Chung y Shin, 2010; Moreira et al., 2017), podemos afirmar que la experiencia electrónica de marca impacta sobre los principales componentes de la confianza, es decir, la integridad, la benevolencia y la capacidad. Por lo tanto, cuanto mayor sea el nivel de percepción positiva de la experiencia electrónica de marca, tanto mayor será la confianza general en el servicio electrónico (Harris y Goode, 2004). De este modo, queda justificada la relación entre la experiencia de marca y la confianza en entornos electrónicos (Moreira et al., 2017; Sarmiento, 2015). 
A la vista de las consideraciones anteriores, se sigue que las características tanto del sitio web como de los medios sociales determinan la confianza en los servicios electrónicos. Por ello, parece plausible formular las hipótesis $\mathrm{H}_{1}$ y $\mathrm{H}_{2}$ para comprobarlas:

$\mathrm{H}_{1}$ Las características de la experiencia electrónica de marca desarrolladas en los sitios web organizacionales tienen un efecto positivo sobre la confianza del usuario.

$\mathrm{H}_{2}$ Las características de la experiencia electrónica de marca desarrolladas en los medios sociales organizacionales tienen un efecto positivo sobre la confianza del usuario.

Numerosas investigaciones prueban que la satisfacción es considerada como un determinante de la intención de compra (Liao, Palvia, y Chen, 2009), concretamente de la fidelización (Moreira et al., 2017). Oliver definió la satisfacción como «la valoración que hace el consumidor de que una característica del producto o servicio o el producto o el servicio en sí mismos, proporciona (o está proporcionando) un resultado de agrado derivado del consumo, incluyendo niveles por debajo o por encima de los esperados (1997:37)». Según Moreira et al. (2017), la satisfacción puede entenderse desde dos perspectivas: la primera se relaciona con la evaluación que hace un cliente después de una determinada experiencia de compra o de consumo; la segunda es el resultado de toda satisfacción previa a una transacción específica.

Según Oliver (1997:4), «un juicio de satisfacción implica un mínimo de dos estímulos: un resultado y un referente de comparación». Con la llegada de las TIC y los medios sociales, y dado el contexto de Oliver (1997), Szymanski y Hise (2000) entendieron la satisfacción electrónica como un juicio de experiencia realizado en Internet por los consumidores en comparación con sus experiencias habidas en las tiendas tradicionales. La diferencia más clara entre los servicios analógicos y los digitales está en la sustitución de la interacción humano-humano en los analógicos por la interacción humano-computadora en los digitales, hecho que puede requerir nuevos enfoques para medir la satisfacción.

La experiencia es el resultado de estimulaciones y de acumulación de valor; por ello, cuantas más estimulaciones agradables genere una marca para un cliente a través de la experiencia electrónica, tanto mayor será la satisfacción del consumidor con la marca y más probabilidades habrá de que quiera utilizar nuevamente sus servicios (Moreira et al., 2017). Pero la satisfacción también es una dimensión afectiva. Por tanto, las experiencias electrónicas de marca pueden ser útiles para estimular la respuesta positiva de un consumidor hacia una marca y también para proporcionar valor adicional que supere sus expectativas.

En un entorno electrónico, la satisfacción ejerce un papel muy importante. Hay muchos modelos empíricos que consideran la satisfacción como un factor determinante en la toma de decisiones de consumo, así como en el desarrollo de las relaciones de los clientes con un producto o servicio (Chung y Shin, 2010). Además, las investigaciones que relacionan la experiencia electrónica con la satisfacción se han desarrollado, tanto en un entorno analógico (Storbacka et al., 1994; Zeithaml, 2000; Roberts et al., 2003) como en un entorno digital (Cristóbal et al., 2007; Liu et al., 2008; Sahadev y Purani, 
2008; Herington y Weaven, 2009; Kim et al., 2009; Moreira et al., 2017). En este sentido, conviene saber que Constantinides (2004) fue el primero en demostrar que la experiencia electrónica tiene un efecto positivo sobre la satisfacción electrónica. Asimismo, Cristóbal et al., (2007) argumentaron que, si se revisa la literatura existente, hay más que evidencias para afirmar que se da una relación entre la experiencia web y la satisfacción electrónica. (Constantinides, 2004; Bansal et al., 2004; Constantinides y Fountain, 2007; Chung y Shin, 2010; Sarmiento, 2018). Por consiguiente, si la dimensión de la satisfacción electrónica condiciona la percepción positiva de la experiencia electrónica por parte del usuario a través de la interactividad, procede formular las hipótesis siguientes:

$\mathrm{H}_{3}$ Las características de la experiencia electrónica de marca desarrolladas en los sitios web organizacionales tienen un efecto positivo sobre la satisfacción del usuario.

$\mathrm{H}_{4}$ Las características de la experiencia electrónica de marca desarrolladas en los medios sociales organizacionales tienen un efecto positivo sobre la satisfacción del usuario.

El compromiso ha sido definido de muchas maneras; entre otras, destacan las siguientes: entenderlo como un componente clave a la hora de establecer y de mantener relaciones a largo plazo (Cater y Zabkar, 2008); entenderlo como la voluntad de desarrollar y de mantener una relación de intercambio positivo (Wu et al., 2009); o la de un deseo permanente de mantener una relación positiva (Moorman et al., 1992); o entenderlo como el apego psicológico a una marca (O’Reilly y Chatman, 1986). La conceptualización del compromiso surgió en la literatura del comportamiento organizacional (Fehr, 1988). Y todas estas definiciones destacan el desarrollo de una relación mutuamente satisfactoria y beneficiosa (Gundlach et al., 1995; Morgan y Hunt, 1994).

En entornos electrónicos, los usuarios son considerados como coproductores en el proceso de consumo de servicios. Estas interacciones entre los usuarios y las marcas están construidas en el transcurso de experiencias episódicas (Chesbrough y Spohrer, 2006), y es en la última instancia cuando se desarrolla el compromiso entre ambas partes (Dai y Salam, 2010). Esto llevó a Mukherjee y Nath (2007) a definir el compromiso electrónico como la asociación natural y el sentido de pertenencia a un sitio web o a un determinado medio social. Por lo tanto, la experiencia electrónica afecta al compromiso entre las partes del intercambio, como probó Ha (2004) en su investigación sobre la relación de las características del sitio web y el compromiso hacia el sitio web.

Según Chung y Shin (2010), la satisfacción y la confianza electrónicas se combinan para proporcionar las condiciones necesarias entre las relaciones usuarios/sitio web o medios sociales y para desarrollar el compromiso electrónico (Morgan y Hunt, 1999; Parvatiyar y Sheth, 2001; Sirdeshmukh et al., 2002 Bhattacharya y Sen, 2003; Fullerton, 2003;). La confianza y la satisfacción electrónicas están consideradas como los antecedentes del compromiso electrónico (Li et al., 2006). La satisfacción suele iniciarse al comienzo de la relación y, según se vayan intensificando la interactividad entre el usuario y el sitio web o medio social de una determinada marca, se empezará a desarrollar la confianza electrónica (Ramaseshan et al., 2006) y, finalmente, el compromiso electrónico. 
Teniendo en cuenta que la confianza y el compromiso son elementos interactivos, es decir, que se desarrollan con la relación, para investigar el efecto de la experiencia electrónica de marca sobre la calidad de la relación (Chung y Shin, 2010; Sarmiento, 2017), planteamos las siguientes hipótesis:

$\mathrm{H}_{5}$ Las características de la experiencia electrónica de marca desarrolladas en los sitios web organizacionales tienen un efecto positivo sobre el compromiso del usuario.

H6 Las características de la experiencia electrónica de marca desarrolladas en los medios sociales organizacionales tienen un efecto positivo sobre el compromiso del usuario.

\subsection{La e-Fidelización como consecuente}

No hacer referencia al concepto de fidelización es casi imposible en el marketing de relaciones. De hecho, marketing de relaciones y marketing de fidelización se asemejan tanto que muchos autores los utilizan como intercambiables (Egan, 2011). La fidelización está considerada como uno de los términos más importantes para explicar la manera en como el consumidor elige entre las diferentes opciones de marca; y es el motivo por el que ha suscitado un gran interés entre los estudiosos y profesionales del marketing. Moreira et al. (2017:25) afirman que «las organizaciones han pasado de captar clientes a retener clientes, por lo que un problema crítico para el éxito continuo de las organizaciones es su capacidad para retener a sus clientes actuales y hacerlos leales a su marca».

Oliver (1997:392) definió la fidelización hacia una marca como «un profundo compromiso de recompra de un producto preferido o servicio, lo que origina repetidas compras en la organización, a pesar de las influencias situacionales o de los esfuerzos de marketing». Más recientemente, Hellier, Geursen, Carr y Rickard (2003:1765) definieron la fidelización como «el grado en que el cliente ha mostrado, en los últimos años, el comportamiento de compra hacia una empresa concreta; y la relevancia de dicho gasto en términos de gasto total del cliente en ese tipo de servicio».

En este sentido, la definición de fidelización está fundamentada en los enfoques de actitudes y comportamientos, lo que sugiere que la fidelidad es un proceso secuencial que indica qué tipo de preferencias muestra el consumidor por una determina marca, lo que implica fases cognitivas, afectivas y conativas dentro del esquema tradicional de decisión de compra. Es decir, la fidelidad incluye inicialmente aspectos psicológicos de evaluación y de toma de decisiones respecto de una marca o de un grupo de marcas similares, así como actitudes y emociones que luego se convierten en comportamientos efectivos y repetitivos de recompra. En esta investigación, la fidelización está entendida como una actitud favorable hacia la utilización de los sitios web o medios sociales organizacionales.

Durante años, una de las dimensiones clave para predecir el comportamiento ha sido la satisfacción global del cliente. Pero en los últimos años el cambio de paradigma hacia un enfoque relacional ha ampliado las dimensiones que predicen las intenciones de comportamiento, entre las que destaca la confianza (Barroso y Martín, 1999). 
Morgan y Hunt (1994) fueron los primeros en demostrar que la confianza ayuda a estimular los intercambios entre los socios. Además, sirve de freno a alternativas a corto plazo en favor de los beneficios esperados a largo plazo al mantenerse con los socios actuales. Moreira et al. (2017) afirman que la confianza reduce la incertidumbre en entornos donde los consumidores se sienten vulnerables. Hoy, para las marcas, es de vital importancia ganarse la confianza del consumidor para forjar su lealtad y reducir el riesgo en las relaciones de intercambio. Hay numerosos trabajos que han probado la relación positiva entre la confianza y la fidelización (Morgan y Hunt, 1994; Garbino y Johnson, 1999; Barroso y Martín, 1999; Chaudhuri \& Holbrook, 2001; Moreira y Silva, 2015; Moreira et al., 2017; Sarmiento, 2018). Ante este contexto, planteamos la siguiente hipótesis:

$\mathrm{H}_{7}$ La confianza electrónica de marca tienen un efecto positivo sobre la fidelización electrónica del usuario.

Una vez analizada la relación existente entre la confianza y la fidelización, pasamos a plantear la relación entre la satisfacción y la fidelización. Durante la revisión de la literatura, encontramos también muchos trabajos de investigación que demuestran la relación entre la satisfacción y la fidelización (Parasuraman et al., 1988; Fornell, 1992; Egan, 2012; Moreira et al., 2017). El autor que más sobresale en demostrarla es Oliver (1999:42), quien prueba que hay «hasta seis asociaciones entre dichos conceptos, pero en el que mejor la describe es en la que señala que la satisfacción no se transforma en fidelidad, sino que como mucho la satisfacción es una semilla que exige alimentación diaria para que la fidelización brote».

Moreira et al., (2017) afirman que la satisfacción del cliente es importante, porque ayuda a las organizaciones a alcanzar sus objetivos financieros y de mercado (Oliver, 1997). Bravo, Matute y Pina (2011) añaden que, si un proveedor de servicios puede satisfacer las necesidades de sus clientes mejor que sus competidores, será fácil hacerlos leales (Moreira y Silva, 2015; Paiva, Sandoval y Bernardin, 2012). Otras investigaciones realizadas sobre los mercados de servicios (Deng et al., 2010, Hellier et al, 2003, Kim y otros, 2004, Lin y Wang, 2006, Ranaweera y Prabhu, 2003, Schlesinger, Cervera, Iniesta y Sánchez, 2014; Sarmiento, 2018) apoyan la existencia de una relación entre la satisfacción y la fidelización de clientes. Ante este contexto, planteamos la siguiente hipótesis:

$\mathrm{H}_{8}$ La satisfacción electrónica de marca tienen un efecto positivo sobre la fidelización electrónica del usuario.

Por último, la relación entre el compromiso y la fidelización también ha sido estudiada por la literatura del marketing. En los mercados, las relaciones hay que construirlas sobre la base del compromiso y del beneficio mutuo a lo largo del tiempo. Porter et al. (1974) afirman que aquellos consumidores que muestren un determinado nivel de compromiso hacia una marca en un contexto electrónico desarrollarán un fuerte vínculo hacia ella. Esto se debe a que el nivel de lealtad mostrado hacia una marca es más fuerte cuando tiene su origen en un compromiso, por lo que puede derivar en una relación estable entre el consumidor y la organización (Prado Román et al., 2014). Así, Von der Heidt y Laberton (2011) 
entienden que el compromiso es un indicador de la fidelización, pues representa el apego emocional o psicológico hacia una marca. Además, el compromiso podemos considerarlo como parte de la fidelización actitudinal hacia una marca (Chaudhuri y Holbrook, 2001).

En los últimos años, varios estudios han examinado la relación entre el compromiso y la lealtad hacia una marca (Morgan y Hunt, 1994, Garbarino y Johnson, 1999, Gruen et al., 2000, Fullerton, 2003, Bansal et al., 2004) y o la recompra en una determinada marca (Harrison-Walker, 2001; Fullerton, 2005a) y muestran un impacto uniformemente positivo entre el compromiso y la fidelidad. Por lo tanto, plateamos la siguiente hipótesis:

$\mathrm{H}_{9}$ El compromiso electrónico hacia una marca tienen un efecto positivo sobre la fidelización electrónica del usuario

En la literatura revisada, queda demostrado que existe una relación entre la experiencia de marca en los sitios web o en los medios sociales de viajes y la fidelización (Brakus et al., 2009; Karjaluoto et al., 2012; Sahin et al., 2012; Nysveen et al., 2013; Moreira et al., 2017; Sarmiento, 2018), pero, como indican los investigadores Prado et al. (2014), no puede distinguirse la naturaleza de la relación entre la experiencia de marca y la fidelización de los clientes (Alén y Fraiz, 2005). Por tanto, no podemos determinar si el efecto de la experiencia de marca se realiza de forma directa sobre la fidelización o si se realiza de forma indirecta a través de variables mediadoras, como es el caso de la satisfacción, la confianza o el compromiso. Ante este contexto, planteamos las siguientes hipótesis:

$\mathrm{H}_{10 a}$ Las características de la experiencia electrónica de marca desarrolladas en los sitios web organizacionales tienen un efecto positivo sobre la lealtad de marca.

$\mathrm{H}_{11 a}$ Las características de la experiencia electrónica de marca desarrolladas en los medios sociales organizacionales tienen un efecto positivo sobre la lealtad de marca.

$\mathrm{H}_{10 \mathrm{~b}}$ Las características de la experiencia electrónica de marca desarrolladas en los sitios web organizacionales tienen un efecto indirecto y positivo sobre la lealtad de marca a través de la confianza

$\mathrm{H}_{11 \mathrm{~b}}$ Las características de la experiencia electrónica de marca desarrolladas en los medios sociales organizacionales tienen un efecto indirecto y positivo sobre la lealtad de marca a través de la confianza.

$\mathrm{H}_{10 c}$ Las características de la experiencia electrónica de marca desarrolladas en los sitios web organizacionales tienen un efecto indirecto y positivo sobre la lealtad de marca a través de la satisfacción

$\mathrm{H}_{11 c}$ Las características de la experiencia electrónica de marca desarrolladas en los medios sociales organizacionales tienen un efecto indirecto y positivo sobre la lealtad de marca a través de la satisfacción. 
$\mathrm{H}_{10 \mathrm{~d}}$ Las características de la experiencia electrónica de marca desarrolladas en los sitios web organizacionales tienen un efecto indirecto y positivo sobre la lealtad de marca a través del compromiso.

$\mathrm{H}_{11 d}$ Las características de la experiencia electrónica de marca desarrolladas en los medios sociales organizacionales tienen un efecto indirecto y positivo sobre la lealtad de marca a través del compromiso.

Una vez presentados los antecedentes teóricos y analizada la relación de las dimensiones de estudio con cada una de las hipótesis, presentamos el modelo siguiente (ver figura 1) para constatarlas empíricamente.

Figura 1

MODELO APLICADO A LA INVESTIGACIÓN

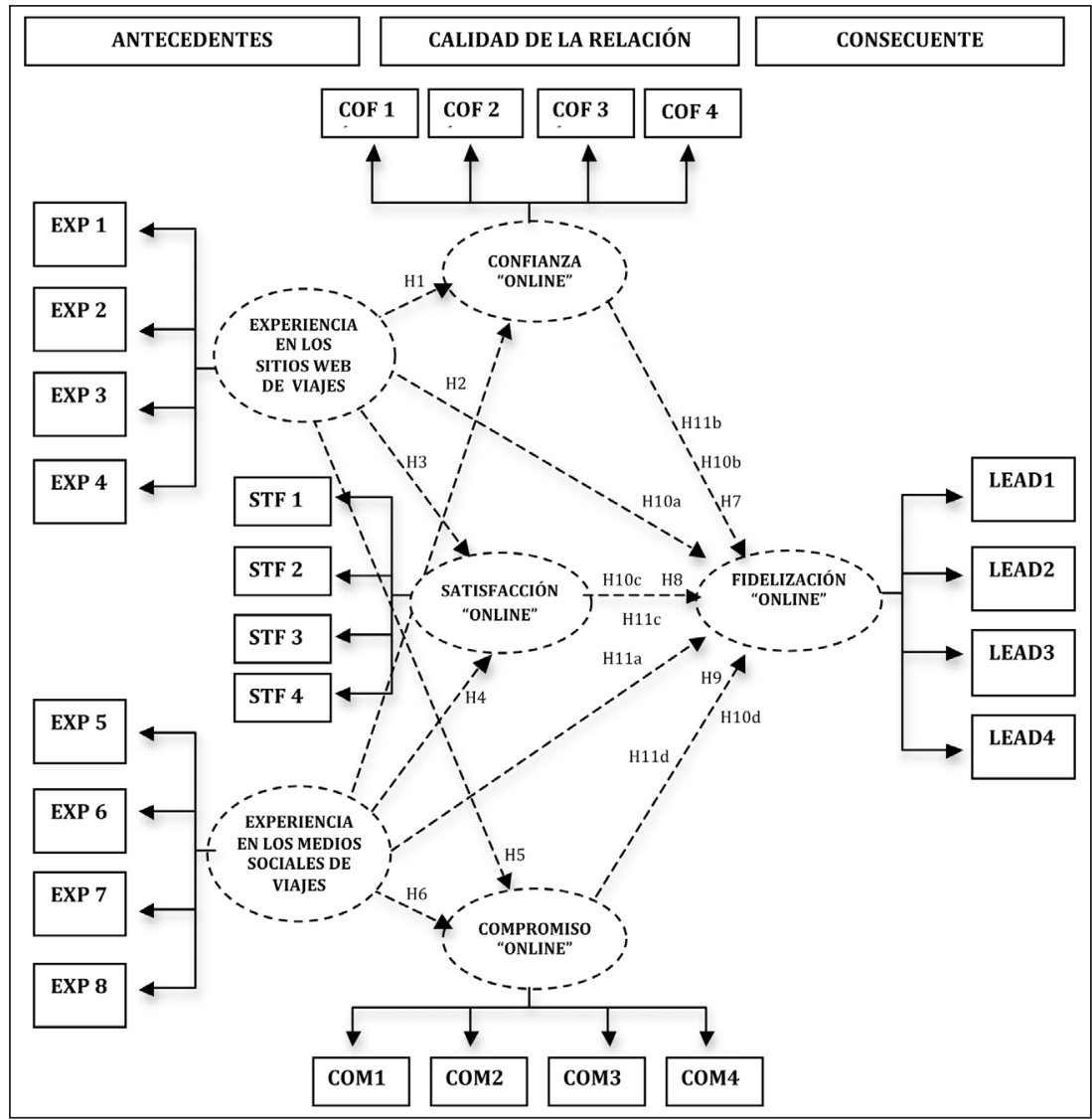

Fuente: Elaboración propia 


\section{METODOLOGÍA}

La metodología empleada para la consecución de los objetivos y la constatación de las hipótesis formuladas se basa en técnicas cuantitativas. Los datos obtenidos fueron recogidos entre usuarios que frecuentaban los sitios web y los medios sociales de viajes para analizar su experiencia de marca y cómo influye esta en la calidad de la relación y la fidelización en un entorno electrónico. Dado este contexto, elegimos a jóvenes universitarios de Grado de la Comunidad de Madrid con edades entre 18 y 25 años por tratarse de los usuarios que más experiencia acumulan en los sitios web y medios sociales de viajes; según estudios de Nielsen (2017), disfrutan de una media de 4 horas y 45 minutos diarios en este tipo de dispositivos. La decisión de elegir una muestra de conveniencia radica en la accesibilidad y proximidad al investigador. En total, repartimos 1200 cuestionarios de los cuales se recibieron 804; 35 de ellos incompletos o negativos y, por lo tanto, eliminados. La muestra final de estudio fue de 769 cuestionarios con un nivel de confianza del 95\%. Previamente, se comprobó la adecuación del cuestionario a través de un pre-test basado en un número reducido de encuestados (65 personas). La muestra fue realizada entre los meses de mayo y junio de 2017.

Para construir el modelo, se utilizó una escala de medición multi-ítem. Las escalas para medir las dimensiones latentes y para asegurarnos la validez de su contenido fueron adaptadas de estudios previos. En todas las escalas, se utilizaron 4 ítems como muestra la tabla 1. En las escalas de experiencia de marca en los sitios web de viajes y en las de experiencia de marca en los medios sociales de viajes, se utilizaron los mismos ítems al tratarse de igual dimensión, pero en distinto contexto.

Para recoger la información, se utilizó la técnica de la encuesta auto-administrada y el cuestionario como herramienta. El cuestionario estaba formado por 29 preguntas relativas a diferentes sitios web y medios sociales turísticos. Tenía tres apartados: el primero consistía en una pregunta filtro para dar mayor validez a nuestro trabajo de investigación; el segundo constaba de veinticuatro preguntas relacionadas con las dimensiones de la experiencia de marca, la calidad de la relación y la fidelización; y el último eran cuatro preguntas sociodemográficas. Para nuestro cuestionario, se utilizaron preguntas estructuradas múltiples, dicotómicas y de escala. Y, para medir las preguntas de escala, se utilizó la de Likert de 7 puntos, donde 1 indicaba que el encuestado estaba muy en desacuerdo y 7 , que estaba muy de acuerdo. A la hora de realizar el cuestionario, a los encuestados se les facilitó una ficha técnica en la que se les clarificaba la diferencia entre los sitios web corporativos de viajes y los medios sociales de viajes. En dicha ficha técnica aparecían ejemplos de páginas web y de medios sociales.

Además, se utilizó la técnica del muestreo estratificado y el muestreo aleatorio simple. Respecto del muestreo estratificado, decidimos dividir la población en estratos siguiendo un criterio relacionado con el objeto del estudio. Dividimos los jóvenes universitarios de la Comunidad de Madrid en dos estratos: universidades públicas (Universidad Rey Juan Carlos) y universidades privadas (Centro universitario ESERP). Como afirma De Esteban Curiel (2007), para aplicar este método, la asignación del tamaño de la muestra de cada estrato admite diversas posibilidades; la más utilizada y la elegida para la investigación es la asignación proporcional en donde la proporción de los ele- 
mentos de la muestra pertenecientes a un estrato presenta la misma proporción que los elementos de la población de ese estrato.

Respecto del muestreo aleatorio, hemos decidido seleccionar sistemáticamente cada elemento de la muestra según la población de cada estrato. En el caso del Centro universitario ESERP, necesitábamos una muestra de 109 unidades y tenía una población de 1500 alumnos. Si dividimos la población $\mathrm{N}$ entre la muestra n, nos da el intervalo $\mathrm{K}=14$; es decir, de cada 14 personas que entraban en la Biblioteca se seleccionaba una hasta llegar a 109 unidades. En el caso de la Universidad Rey Juan Carlos, la población era de 41.476 alumnos y la muestra es de 660 unidades, lo que da un intervalo de $\mathrm{K}=63$; es decir, de cada 63 personas que entraban en la Biblioteca se seleccionaba una hasta llegar a 660 unidades. Importa saber que el momento de realización de la encuesta eran fechas de exámenes, lo que aumentó en un porcentaje bastante elevado el número de unidades. Para el análisis e interpretación de los resultados, se utilizó el SPSS 20.0 para la distribución de frecuencias, promedios, medidas de dispersión y el SPSS Amos 20.0, para la interpretación del análisis estructural.

Tabla 1

ÍTEMS UTILIZADOS PARA EVALUAR LA EXPERIENCIA DE MARCA, LA CALIDAD DE LA RELACIÓN Y LA FIDELIZACIÓN

\begin{tabular}{|c|c|c|}
\hline Ítems & Abreviaturas & Referencia \\
\hline \multicolumn{3}{|l|}{ Experiencia de marca en los sitios web de viajes } \\
\hline Este sitio web tiene buena selección de servicios & EXP1 & \multirow{4}{*}{$\begin{array}{l}\text { Constantinides } \\
\text { (2004); Sarmientc } \\
\text { (2017); Moreira } \\
\text { et al., (2017) }\end{array}$} \\
\hline Este sitio web protege la seguridad de los usuarios & EXP2 & \\
\hline Este sitio web proporciona información precisa & EXP3 & \\
\hline Este sitio web dispone de herramientas para comunicarse & EXP4 & \\
\hline \multicolumn{3}{|l|}{ Experiencia de marca en los medios sociales de viajes } \\
\hline Este sitio web tiene buena selección de servicios & EXP5 & \multirow{4}{*}{$\begin{array}{l}\text { Constantinides } \\
\text { (2004); Sarmiento } \\
\text { (2017); Moreira } \\
\text { et al., (2017) }\end{array}$} \\
\hline Este sitio web protege la seguridad de los usuarios & EXP6 & \\
\hline Este sitio web proporciona información precisa & EXP7 & \\
\hline Este sitio web dispone de herramientas para comunicarse & EXP8 & \\
\hline \multicolumn{3}{|l|}{ Confianza hacia la marca } \\
\hline Esta marca es honesta & COF1 & \multirow{4}{*}{$\begin{array}{l}\text { Prado et al., } \\
(2014) ; \text { Sarmiento } \\
\text { (2017); Moreira } \\
\text { et al., (2017) }\end{array}$} \\
\hline Esta marca no es oportunista & $\mathrm{COF} 2$ & \\
\hline Esta marca se preocupa por sus clientes & $\mathrm{COF} 3$ & \\
\hline Esta marca protege a sus clientes & $\mathrm{COF} 4$ & \\
\hline
\end{tabular}




\begin{tabular}{|c|c|c|}
\hline Ítems & Abreviaturas & Referencia \\
\hline \multicolumn{3}{|l|}{ Satisfacción hacia la marca } \\
\hline Yo estoy muy satisfecho con lo que ofrece esta marca & STF1 & \multirow{4}{*}{$\begin{array}{l}\text { Prado } \text { et al., } \\
\text { (2014); Sarmiento } \\
\text { (2017); Moreira } \\
\text { et al., (2017) }\end{array}$} \\
\hline $\begin{array}{l}\text { Yo estoy muy satisfecho con la profesionalidad de esta } \\
\text { marca }\end{array}$ & STF2 & \\
\hline Yo estoy muy satisfecho con la elección de esta marca & STF3 & \\
\hline Creo que hice lo correcto al elegir esta marca & STF4 & \\
\hline \multicolumn{3}{|l|}{ Compromiso hacia la marca } \\
\hline Defendería esta marca si otros la criticaran & COM1 & \multirow{4}{*}{$\begin{array}{l}\text { Prado et al., } \\
\text { (2014); Sarmiento } \\
(2014) ;\end{array}$} \\
\hline $\begin{array}{l}\text { Me siento muy identificado con los valores de esta } \\
\text { marca }\end{array}$ & COM2 & \\
\hline Me siento identificado con la información de esta marca & COM3 & \\
\hline $\begin{array}{l}\text { Creo que voy a desarrollar una relación a largo plazo } \\
\text { con esta marca }\end{array}$ & COM4 & \\
\hline \multicolumn{3}{|l|}{ Lealtad hacia la marca } \\
\hline Mi preferencia por esta marca no va a cambiar & LEAD1 & \multirow{4}{*}{$\begin{array}{l}\text { Prado et al., } \\
\text { (2014); Srmiento, } \\
\text { (2014); Moreira } \\
\text { et al., (2017); } \\
\text { Sarmiento (2018) }\end{array}$} \\
\hline $\begin{array}{l}\text { No voy a cambiar de marca aunque me hablen mal de } \\
\text { ella }\end{array}$ & LEAD2 & \\
\hline Me considero leal a esta marca & LEAD3 & \\
\hline Si tuviera que elegir nuevamente, elegiría esta marca & LEAD4 & \\
\hline
\end{tabular}

Fuente: elaboración propia

\section{ANÁLISIS DE LOS RESULTADOS}

En este apartado, se analizan y presentan los resultados de los datos obtenidos de las 769 encuestas realizadas a los usuarios de los sitios web y los medios sociales de servicios turísticos. Los porcentajes ofrecidos en las siguientes tablas están calculados en función del tamaño de la muestra de 769 encuestas a través del muestreo aleatorio simple. Este método ha permitido obtener una muestra que, tanto en tamaño como en forma, es representativa de la sociedad objeto de estudio.

A continuación, presentamos los resultados de la demografía de los usuarios encuestados; para ello, utilizamos un análisis descriptivo de frecuencias. En la pregunta número uno, se preguntaba por el sexo, el 42,9\% de los encuestados eran varones y el 57,1\%, mujeres. Sobre las edades de los usuarios, el 21,2\% de los encuestados tenía entre 18-19 años; el 36,5\%, entre 20-21 años, la muestra más representativa; el 23,5\% tenía entre 22-23 años; y, por último, el 18,8\% tenía más de 24 años. Respecto del nivel de ingresos, la mayoría de los encuestados, el 76,18\% tenía un nivel medio; el 17,85\%, un nivel medio-bajo; el 5,97\%, un nivel medio-alto. Esta variable analizada del nivel de ingresos hace referencia a la situación familiar. La mayoría de los encuestados tenía la nacionalidad española: el 87,1\% eran españoles, y el 12,9\% eran extranjeros. Las nacionalidades extranjeras eran la china, rumana, británica, francesa, italiana, colombiana, venezolana, ecuatoriana y alemana. 
Tabla 2

ANÁLISIS FACTORIAL CONFIRMATORIO

\begin{tabular}{|c|c|c|c|c|c|c|}
\hline Ítem & $\begin{array}{l}\text { Medial } \\
\text { Desviación }\end{array}$ & $\begin{array}{l}\text { Cargas } \\
\text { estandarizadas }\end{array}$ & Valot t & $\begin{array}{l}\text { Alfa de } \\
\text { Cronbach }\end{array}$ & $A V E$ & $\begin{array}{l}\text { Fiabilidad } \\
\text { Compuesta }\end{array}$ \\
\hline EXP1 & $2,98 / 0,743$ & 0,897 & 21,645 & \multirow{4}{*}{0,858} & \multirow{4}{*}{0,785} & \multirow{4}{*}{0,956} \\
\hline EXP2 & $3,18 / 0,803$ & 0,812 & 20,123 & & & \\
\hline EXP3 & $2,78 / 0,798$ & 0,798 & 20,145 & & & \\
\hline EXP4 & $3,26 / 0,827$ & 0,713 & 18,345 & & & \\
\hline EXP5 & $5,92 / 0,786$ & 0,856 & 20,345 & \multirow{4}{*}{0,897} & \multirow{4}{*}{0,798} & \multirow{4}{*}{0,912} \\
\hline EXP6 & $4,67 / 0,994$ & 0,796 & 19,375 & & & \\
\hline EXP7 & $6,12 / 0,879$ & 0,847 & 22,475 & & & \\
\hline EXP8 & $5,98 / 0,867$ & 0,794 & 23,645 & & & \\
\hline COF1 & $4,98 / 0,789$ & 0,879 & 18,136 & \multirow{4}{*}{0,895} & \multirow{4}{*}{0,768} & \multirow{4}{*}{0,848} \\
\hline COF2 & $5,23 / 0,834$ & 0,745 & 20,354 & & & \\
\hline COF3 & $4,13 / 0,897$ & 0,784 & 24,756 & & & \\
\hline $\mathrm{COF} 4$ & $4,67 / 0,897$ & 0,798 & 25,657 & & & \\
\hline STF1 & $5,13 / 0,789$ & 0,987 & 21,274 & \multirow{4}{*}{0,935} & \multirow{4}{*}{0,832} & \multirow{4}{*}{0,931} \\
\hline STF2 & $5,34 / 0,845$ & 0,913 & 22,476 & & & \\
\hline STF3 & $5,68 / 0,888$ & 0,908 & 22,892 & & & \\
\hline STF4 & $6,12 / 0,728$ & 0,897 & 21,839 & & & \\
\hline COM1 & $5,34 / 0,723$ & 0,820 & 18,937 & \multirow{4}{*}{0,836} & \multirow{4}{*}{0,793} & \multirow{4}{*}{0,863} \\
\hline $\mathrm{COM} 2$ & $4,23 / 0,754$ & 0,892 & 20,615 & & & \\
\hline COM3 & $4,79 / 0,897$ & 0,883 & 20,689 & & & \\
\hline COM4 & $5,98 / 0,734$ & 0,812 & 19,487 & & & \\
\hline LEAD1 & $5,38 / 0,823$ & 0,807 & 21,784 & \multirow{4}{*}{0,836} & \multirow{4}{*}{0,838} & \multirow{4}{*}{0,846} \\
\hline LEAD2 & $5,13 / 0,729$ & 0,831 & 22,483 & & & \\
\hline LEAD3 & $5,67 / 0,853$ & 0,794 & 19,689 & & & \\
\hline LEAD4 & $5,38 / 0,802$ & 0,811 & 17,345 & & & \\
\hline
\end{tabular}

$\mathrm{X} 2(\mathrm{~g} .1 .=376)=845,596(\mathrm{p}=0,000) ; \mathrm{NFI}=0,867 ; \mathrm{NNFI}=0,937 ; \mathrm{CFI}=0,948 ; \mathrm{IFI}=0,965 ; \mathrm{GFI}=0,834 ; \mathrm{AGFI}=0,785$; RMSEA $=0,075$

Fuente: Elaboración propia

En la pregunta filtro se les preguntó por la frecuencia de uso de los sitios web y medios sociales turísticos. El dato más significativo fue que el 56,96\% (458 de 804) de los encuestados utiliza varias veces al año los sitios web de viajes y el menos significativo: el 4,35\% (35 de 804) de los encuestados nunca ha utilizado un sitio web de viajes, razón por la que excluimos a estos últimos del resto de preguntas excepto de las socio- demográficas. Por último, señalaremos que los demás resultados de esta variable: el 9,1\% (73 de los 804 
usuarios) utiliza los sitios web y medios sociales de viajes semanalmente; el 14,56\% (117 de los 804 usuarios), mensualmente; y, por último, el 15,03\% (121 de los 804 usuarios) solo los ha utilizado una vez al año.

Respecto del apartado cuantitativo, sometimos el cuestionario a un análisis factorial confirmatorio donde todas las cargas y valores " $\mathrm{t}$ " significativos fueron menores a un valor $\mathrm{p}<.01$. Para medir la fiabilidad del cuestionario utilizado, se aplicó el alfa de Cronbach, obteniéndose valores superiores a 0,60 como indica Hair et al., (2010). En segundo lugar, se utilizó un análisis de fiabilidad compuesta en la que se obtuvieron resultados superiores a 0,70, como también indican Hair et al., (2010). Por último, se recurrió a un análisis de la varianza extraída promedio, donde los resultados fueron superiores a.50 (Hair et al., 2010). En la tabla 2, se presentan todos los resultados del análisis factorial confirmatorio. De este modo, se confirma que los ítems propuestos son medidores fiables de las citadas dimensiones latentes.

Una vez demostrada la fiabilidad del instrumento, recurrimos a su validez. Para ello, utilizamos la validez discriminante que mide el grado en que una determinada dimensión es diferentes del resto. En la tabla 3, se puede observar que ninguno de los valores de confianza incluye el valor 1 . Podemos concluir, pues, que los factores utilizados en el modelo tienen una fiabilidad y validez adecuadas.

Tabla 3

RESULTADOS DE LA VALIDEZ DISCRIMINANTE

\begin{tabular}{lcccccc}
\hline & 1 & 2 & 3 & 4 & 5 & 6 \\
\hline Experiencia (sitios web) & 0,834 & & & & & \\
Experiencia(medios sociales) & 0,548 & 0,912 & & & & \\
Confianza & 0,647 & 0,738 & 0,893 & & & \\
Satisfacción & 0,456 & 0,573 & 0,675 & 0,945 & & \\
Compromiso & 0,475 & 0,463 & 0,789 & 0,795 & 0,916 & \\
Fidelización & 0,567 & 0,497 & 0,567 & 0,420 & 0,729 & 0,879 \\
\hline
\end{tabular}

Fuente: elaboración propia

Leyenda: (1) Experiencia (sitios web); (2) Experiencia (medios sociales); (3) Confianza; (4) Satisfacción; (5) Compromiso; (6) Fidelización.

En la tabla 4, presentamos la constatación de las hipótesis con un modelo de ecuaciones estructurales mediante el método de máxima verosimilitud (Hair et al., 2010). Respecto de la influencia que tiene la experiencia de marca en los sitios web de viajes sobre la calidad de la relación electrónica, los resultados mostraron que solo la experiencia en los sitios web tiene una relación positiva en la satisfacción $(\beta=0,245 ; \mathrm{p}<0,01)$, por lo que se procede a aceptar la hipótesis 3 y se rechaza las hipótesis 1 y 5 . Referente a la influencia 
que tiene la experiencia de marca en los medios sociales de viajes sobre la calidad de la relación electrónica, podemos afirmar que existe una relación positiva entre la experiencia de marca en los medios sociales y la confianza $(\beta=0,457 ; \mathrm{p}<0,01)$, la experiencia de marca en los medios sociales y la satisfacción $(\beta=0,354 ; \mathrm{p}<0,01)$, la experiencia de marca en los medios sociales y el compromiso $(\beta=0,542 ; \mathrm{p}<0,01)$, por lo que quedan aceptadas las hipótesis 2, 4 y 6 . Además, el estudio mostró una relación positiva entre la confianza y la fidelización ( $\beta=0,375 ; \mathrm{p}<0,01)$, lo que permite aceptar la hipótesis 7 . Los resultados también mostraron que existe una relación positiva entre la satisfacción y la fidelización ( $\beta=$ 0,492; $\mathrm{p}<0,01)$. Por consiguiente, se acepta la hipótesis 8 . Los resultados de la hipótesis 9 sobre la relación positiva entre el compromiso y la fidelización prueban dicha relación $(\beta=$ 0,527; $\mathrm{p}<0,01)$. Por último, plateábamos la relación directa entre la experiencia de marca en los sitios web y medios sociales de viaje y la fidelización, los resultados muestran que la experiencia de marca en los medios sociales también tiene un efecto positivo sobre la fidelización $(\beta=0,287 ; p<0,01)$, pero no la tiene la experiencia de marca en los sitios de viajes, por lo que se rechaza la hipótesis 10a y que aceptada la hipótesis 11a.

\section{Tabla 4}

\section{MODELO ESTRUCTURAL PROPUESTO PARA ANALIZAR LA RELACIÓN ENTRE LA EXPERIENCIA DE MARCA EN LOS SITIOS WEB DE VIAJES, LA EXPERIENCIA DE MARCA EN LOS MEDIOS SOCIALES DE VIAJES, LA CALIDAD DE LA RELACIÓN Y LA FIDELIZACIÓN}

\begin{tabular}{llll}
\hline Hipótesis & Relación entre dimisiones & $\begin{array}{l}\text { Cargas } \\
\text { estandarizadas }\end{array}$ & Valor t \\
\hline H1 & Experiencia de marca(sitios web)-Confianza & $-0,022$ & $-0,438$ \\
H2 & Experiencia de marca(medios sociales)-Confianza & $0,457 * *$ & 9,546 \\
H3 & Experiencia de marca(sitios web)-Satisfacción & $0,245^{* *}$ & 8,836 \\
H4 & Experiencia de marca(medios sociales)-Satisfacción & $0,354 * *$ & 12,457 \\
H5 & Experiencia de marca(sitios web)-Compromiso & $-0,064$ & $-1,547$ \\
H6 & Experiencia de marca(medios sociales)-Compromiso & $0,542 * *$ & 7,839 \\
H7 & Confianza-fidelización & $0,375^{* *}$ & 10,368 \\
H8 & Satisfacción-fidelización & $0,492 * *$ & 11,369 \\
H9 & Compromiso-fidelización & $0,527 * *$ & 9,739 \\
H10a & Experiencia de marca(sitios web)-Fidelización & $-0,095$ & $-1,590$ \\
H11a & Experiencia de marca(medios sociales)-Fidelización & $0,287 * *$ & 7,937 \\
\hline
\end{tabular}

$* \mathrm{P}<0,05 ; * * \mathrm{P}<0,01 ; \mathrm{n}=769$

$\mathrm{R}^{2}=0,664 ; \mathrm{x} 2(\mathrm{p})=44,844(0,000) ; \mathrm{NNFI}=0,923 ; \mathrm{CFI}=0,943 ; \mathrm{IFI}=0,975 ; \mathrm{RMSA}=0,078$

Fuente: elaboración propia 


\section{Figura 2 \\ COEFICIENTES ESTANDARIZADOS DEL MODELO ESTRUCTURAL (RELACIÓN DIRECTA)}

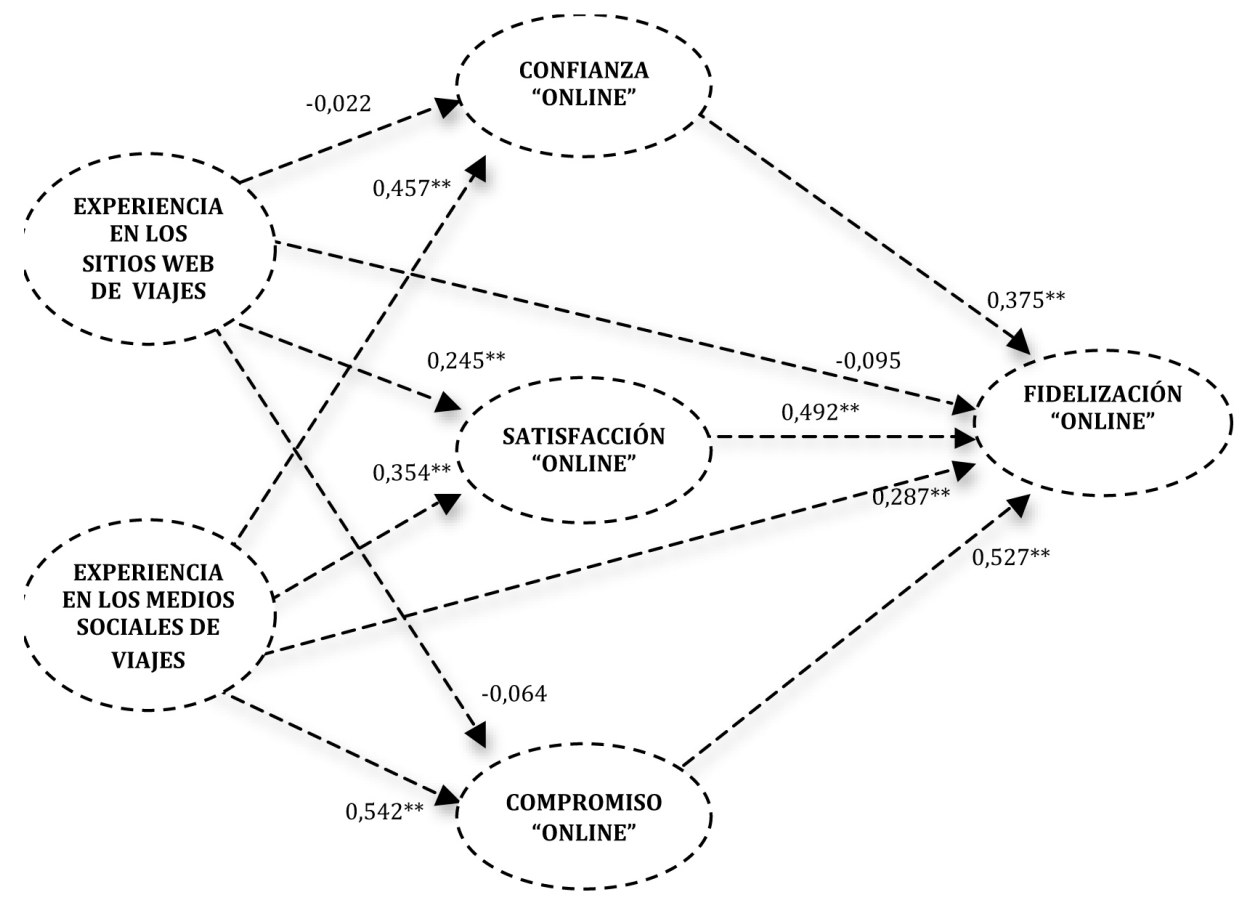

Fuente: Elaboración propia.

En la tabla 5, se muestran las relaciones indirectas de la experiencia de marca en los sitios web y medios sociales de viaje sobre la lealtad a través de las distintas dimensiones de estudio (confianza, satisfacción y compromiso). Como se puede observar, la relación de la experiencia de marca en los medios sociales tiene un efecto positivo a través de la confianza $(\beta=0,353 ; p<0,01)$, a través de la satisfacción $(\beta=0,492 ; \mathrm{p}<0,01)$ y a través del compromiso $(\beta=0,391 ; \mathrm{p}<0,01)$, por lo que se pueden aceptar las hipótesis $11 \mathrm{~b}, 11 \mathrm{c}$ y 11d. Por el contrario, solo existe una relación positiva entre la experiencia de marca en los sitios web de viajes y la lealtad a través de la satisfacción $(\beta=0,391 ; \mathrm{p}<0,01)$, por lo que se acepta la hipótesis 10c y se rechazan las hipótesis 10 b y $10 \mathrm{~d}$. 
Tabla 5

RELACIÓN INDIRECTA ENTRE LA EXPERIENCIA DE MARCA EN LOS SITIOS WEB Y MEDIOS SOCIALES DE VIAJE Y LA FIDELIZACIÓN A TRAVÉS DE LA CONFIANZA, LA SATISFACCIÓN Y EL COMPROMISO

\begin{tabular}{|c|c|c|c|}
\hline Hipótesis & Relación entre dimensiones & $\begin{array}{l}\text { Cargas } \\
\text { estandarizadas }\end{array}$ & Valor $\mathrm{t}$ \\
\hline $\mathrm{H} 10 \mathrm{~b}$ & $\begin{array}{l}\text { Experiencia de marca(sitios web)-Confianza- } \\
\text { Lealtad }\end{array}$ & $-0,038$ & $-1,438$ \\
\hline $\mathrm{H} 10 \mathrm{c}$ & $\begin{array}{l}\text { Experiencia de marca(sitios web)-Satisfacción- } \\
\text { lealtad }\end{array}$ & $0,298 * *$ & 7,182 \\
\hline H10d & $\begin{array}{l}\text { Experiencia de marca(sitios web)-Compromiso- } \\
\text { lealtad }\end{array}$ & $-0,024$ & $-1,547$ \\
\hline $\mathrm{H} 11 \mathrm{~b}$ & $\begin{array}{l}\text { Experiencia de marca(medios sociales)-Confianza- } \\
\text { lealtad }\end{array}$ & $0,353^{* *}$ & 8,298 \\
\hline $\mathrm{H} 11 \mathrm{c}$ & $\begin{array}{l}\text { Experiencia de marca(medios sociales)- } \\
\text { Satisfacción-lealtad }\end{array}$ & $0,492 * *$ & 10,428 \\
\hline H11d & $\begin{array}{l}\text { Experiencia de marca(medios sociales)- } \\
\text { Compromiso-lealtad }\end{array}$ & $0,391 * *$ & 11,829 \\
\hline
\end{tabular}

$* \mathrm{P}<0,05 ; * * \mathrm{P}<0,01 ; \mathrm{n}=769$

Fuente: elaboración propia

Figura 3

COEFICIENTES ESTANDARIZADOS DEL MODELO ESTRUCTURAL (RELACIÓN INDIRECTA ENTRE EXPERIENCIA EN LOS SITIOS WEB DE VIAJES-CALIDAD DE LA RELACIÓN-FIDELIZACIÓN)

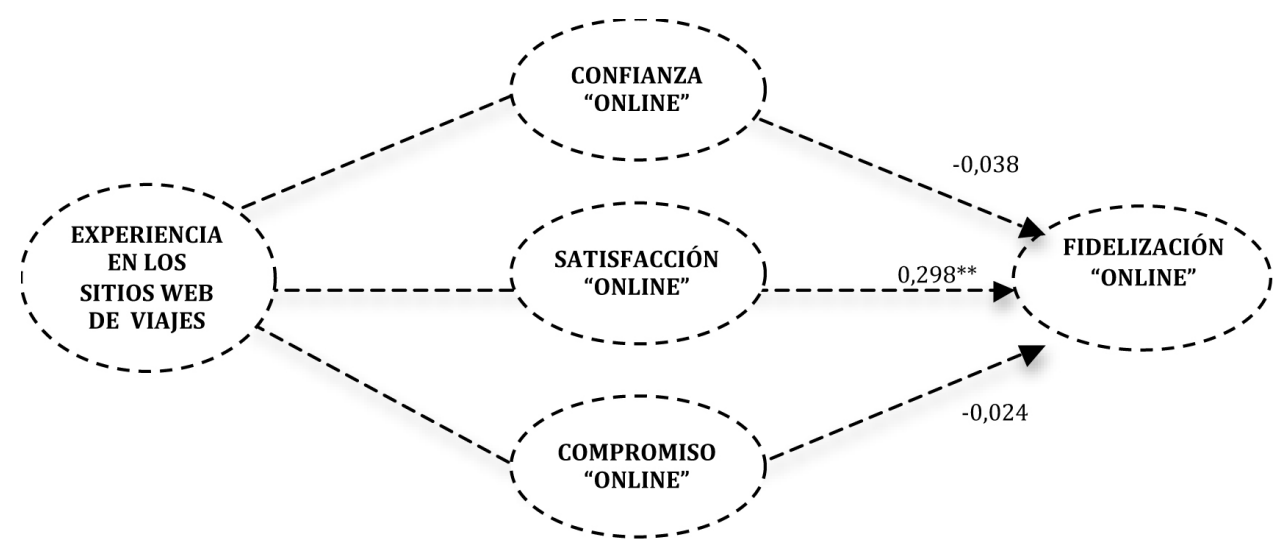

Fuente: Elaboración propia. 
Figura 4

COEFICIENTES ESTANDARIZADOS DEL MODELO ESTRUCTURAL (RELACIÓN INDIRECTA ENTRE LA EXPERIENCIA EN LOS MEDIOS SOCIALES DE VIAJES-CALIDAD DE LA RELACIÓN-FIDELIZACIÓN)

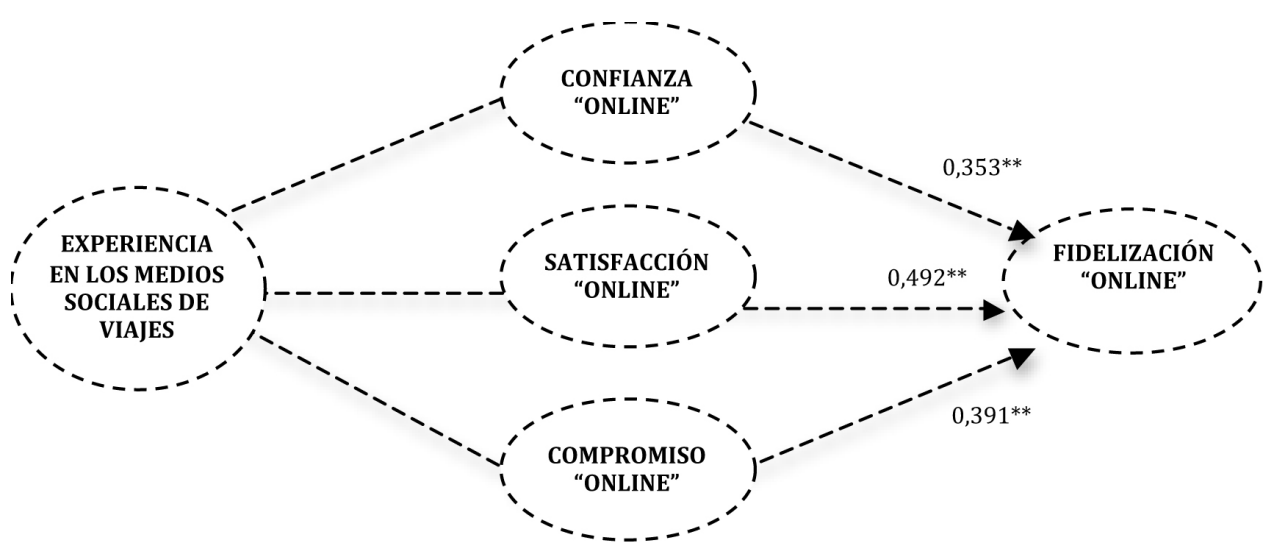

Fuente: Elaboración propia.

\section{CONCLUSIONES, IMPLICACIONES PRÁCTICAS, LIMITACIONES Y FUTURAS LÍNEAS DE INVESTIGACIÓN}

La principal conclusión de este estudio es que la experiencia de marca es un antecedente muy importante de la confianza, de la satisfacción, del compromiso y de la fidelización de marca. Sin embargo, la influencia de la experiencia de marca a través de los medios sociales o a través de los sitios web corporativos es distinta de lo que se pensaba originariamente. Del modelo propuesto, podemos concluir que la experiencia de marca a través de los medios sociales es el predictor directo más importante de la calidad de la relación y de la fidelización de marca. No obstante, la experiencia de marca a través de los sitios web corporativos no muestra esa relación significativa.

La experiencia de marca es un concepto relativamente nuevo en marketing. Surge de la interacción de los clientes con estímulos relacionados con la marca. Las experiencias de marca pueden generar lealtad o incrementar la percepción de confianza y de satisfacción. Como el mercado turístico electrónico de viajes ha experimentado profundos cambios en los últimos años, se ha vuelto mucho más competitivo y ha originado que las organizaciones turísticas utilicen los sitios web corporativos o los medios sociales para desarrollar experiencias únicas o placenteras para el consumidor en vez de enfocarlo como un simple sitio web de transacción. Por lo tanto, cuando las marcas ofrecen estímulos únicos e intensos, utilizando anuncios de impacto visual, logotipos llamativos, juegos interactivos, bandas sonoras que pueden generar placer, imágenes o comentarios de otros clientes, estarán haciendo que los usuarios deseen repetir su experiencia por el recuerdo duradero que dejan en sus mentes. 
Las experiencias de marca pueden conducir a la lealtad del cliente y aumentar la calidad de la relación. Por lo tanto, pueden ser utilizadas por las organizaciones turísticas de viajes para aumentar el valor para el proveedor y para el cliente y para trabajar ventajosa y competitivamente. En un mercado en donde los productos o servicios son a veces similares y las estrategias de diferenciación ya resultan ineficaces, ofrecer al cliente experiencias agradables es una manera poderosamente eficaz de diferenciar un proveedor y hacerlo único para su cliente.

\subsection{Implicaciones prácticas}

De las implicaciones en el ámbito del mercado turístico electrónico, podemos afirmar que conseguir nuevos clientes es más costoso y difícil que conservar los existentes. Como sugiere esta investigación, dimensiones como la confianza, la satisfacción, el compromiso o la fidelización son importantes para que las organizaciones turísticas establezcan una base de datos y a partir de ella aumenten los niveles de fidelización mediante la personalización del servicio. En consecuencia, para aumentar la fidelización, las organizaciones turísticas tienen que utilizar herramientas que los clientes perciban como de calidad y así desarrollar una experiencia electrónica de calidad, como la existente en los medios sociales en comparación con la de los sitios web corporativos. Cuanto mayor sea el nivel de calidad de relación, tanto mayor será el nivel de fidelización.

A continuación, describimos algunas de las estrategias que pueden desarrollar los sitios web de viajes a través de sus medios sociales: (1) La mayoría de los usuarios utiliza vídeos para decidir a qué lugar quiere ir de vacaciones, en este sentido, las agencias de viajes online podrían utilizar herramientas como YouTube para crear guías turísticas de diversas zonas elaboradas por los usuarios a través de sus propias experiencias; (2) Otra estrategia para generar fidelidad a la marca es dotar a las marcas hoteleras o aéreas de personalidad; en este sentido, las empresas turísticas podrían utilizar herramientas como Instagram para crear una comunidad "lifestile" en torno a la marca, además de ser considerada el medio social que más crece en número de usuarios en los últimos años; (3) Otra de las herramientas que pueden utilizar las empresas turísticas es Twitter o Linkedin, y de forma rápida y eficaz pueden mejorar la comunicación y atención al cliente las 24 horas y los 365 días al año; (4) Los blogs turísticos no solo son herramientas para poner información de la empresa, sino que también son herramientas muy importantes para generar valor para los clientes a través del contenido, pues de una manera o de otra dichas herramientas pueden ser utilizadas por las empresas turísticas para captar clientes potenciales.

Las herramientas que las organizaciones turísticas elijan para gestionar las relaciones con sus clientes son de vital importancia; a través de ellas, se realiza el primer encuentro con el cliente, se desarrolla el proceso de compra y el servicio postventa. Durante estos procesos de prestación de servicios, el cliente busca organizaciones honestas que satisfagan sus necesidades y que se sientan comprometidas con él. Y, como demuestra esta investigación, los medios sociales son los que mejor satisfacen estas necesidades. 


\subsection{Limitaciones de investigación}

Las principales limitaciones de investigación las comentamos a continuación: La primera de ellas fue el tamaño de la muestra analizada. La decisión de elegir esta muestra de conveniencia radica en la accesibilidad, la rapidez, lo económico, la facilidad y, sobre todo, la cercanía por parte de los sujetos al investigador. Dicho esto, analizamos a 679 usuarios, lo que representa un 0,18\% del total de estudiantes de Grado de las universidades en la Comunidad de Madrid. Por motivos económicos y de movilidad, el análisis lo realizamos solo en la Comunidad de Madrid, aunque lo justificamos diciendo que era la Comunidad de España en la que más se utilizaban los medios sociales entre los jóvenes. Ante este contexto, podemos afirmar que los datos hallados no los podemos extrapolar a toda la población de estudiantes de Grado de España.

La segunda limitación de nuestro trabajo de investigación fue elegir las dimensiones de confianza, satisfacción y compromiso como antecedentes de la fidelización. Su elección se debe a que son las dimensiones más utilizadas y fáciles de investigar, pero sería interesante tener en cuenta las promociones de las marcas, el precio o los programas de fidelización como antecedentes de la fidelización.

\subsection{Futuras líneas de investigación}

Para futuras líneas de investigación, recomendamos aplicar el modelo a todo el ámbito geográfico, como puede ser el caso de España o realizar un análisis comparativo de varios países. Además, recomendamos aplicar la investigación a toda la población que use los sitios web turísticos y medios sociales para vivir una experiencia turística, sin limitarla a un rango de edad y profesión como hemos hecho nosotros en nuestra investigación. También, cabe sugerir la necesidad de analizar la relación entre la experiencia de marca y la imagen de marca (de qué manera las experiencias cambian la percepción del cliente de una marca) o el valor de la marca, tras haber probado positivamente la relación entre experiencias y fidelización.

En nuestro trabajo de investigación, nos hemos centrado en la experiencia de marca, pero para futuras líneas de investigación sería correcto analizar los antecedentes de las experiencias de marca y cómo influyen en la calidad de servicio, la confianza, la satisfacción, el compromiso o la fidelización.

Por último, identificamos las necesidad de realizar un estudio de los medios sociales en sector turístico y ver cuáles son los que más se utilizan y qué les lleva a utilizarlos. Esta investigación nos llevaría a conocer el grado de interactividad entre los proveedores turísticos y los usuarios.

\section{BIBLOGRAFÍA}

ALALWAN, A.A., RANA, N.P., DWIVEDI, Y.K. y ALGHARABAT, R. (2017): «Social media in marketing: A review and analysis of existing literature». Telematics and Informatics, vol. 34, $\mathrm{n}^{\mathrm{o}} 7$, p. 1.177-1.190. 
ALÉN-GONZÁLEZ, M.E. y FRAIZ-BREA, J. (2005): «Calidad de Servicio y Satisfacción, Antecedente o Consecuente? Su Evaluación en el Ámbito del Turismo Termal». Revista Portuguesa de Marketing, vol. 17, $\mathrm{n}^{\circ}$ 1, pp. 61-76.

ATHANASOPOULOU, E., TOMBROU, M., PANDIS, S.N. y RUSSELL, A. G. (2008): «The role of sea-salt emissions and heterogeneous chemistry in the air quality of polluted coastal areas». Atmospheric Chemistry and Physics Discussions, vol. 8, n 1, pp. 3.807-3.841.

ATHANASOPOULOU, P. (2009): «Relationship quality: a critical literature review and research agenda». European Journal of Marketing, vol. 43, n ${ }^{\circ}$ 5/6, pp. 583-610.

BANSAL, H.S., IRVING, P.G. y TAYLOR, S.F. (2004). «A three-component model of customer to service providers». Journal of the Academy of marketing Science, vol. 32, $\mathrm{n}^{\mathrm{o}} 3$, pp. 234-250.

BARNES, S.J. y VIDGEN, R.T. (2002): «An integrative approach to the assessment of e-commerce quality». J. Electron. Commerce Res., vol. 3, nº 3, pp. 114-127.

BARROSO, C. y MARTÍN, E. (1999): Marketing relacional. Esic.Bhattacharya y Sen, 2003;

BLIEMEL, M. y HASSANEIN, K. (2007). Consumer satisfaction with online health information retrieval: a model and empirical study. E-service Journal, vol. 5, n ${ }^{\circ} 2$, pp. 53-84.

BRAKUS, J.J., SCHMITT, B. y ZARAN- TONELLO, L. (2009): «Brand experience: What is it? How is it measured? Does it affect loyalty?». Journal of Marketing, vol. $73, \mathrm{n}^{\mathrm{o}} 3$, pp. 52-68.

BRAVO, R., MATUTE, J. y PINA, J.M. (2011): «Efectos de la imagen corporativa en el comportamiento del consumidor: Un estudio aplicado a la banca comercial». Innovar, vol. 21, n 40, pp. 35-52.

CATER, B. y ZABKAR, V. (2009): «Antecedents and consequences of commitment in marketing research services: The client's perspective». Industrial Marketing Management, vol. 38, nº 7, pp. 785-797.

CHAFFEY, D. y ELLIS-CHADWICK, F. (2012): Digital marketing. Pearson Higher Ed.

CHAUDHURI, A. y HOLBROOK, M. B. (2001): «The chain of effects from brand trust and brand affect to brand performance: the role of brand loyalty». Journal of marketing, vol. 65, $\mathrm{n}^{\mathrm{o}} 2$, pp.81-93.

CHESBROUGH, H. y SPOHRER, J. (2006): «A research manifesto for services science». Communications of the ACM, vol. 49, $\mathrm{n}^{\circ} 7$, pp. 35-40.

CHO, N. y PARK, S. (2001): «Development of electronic commerce user-consumer satisfaction index (ECUSI) for Internet shopping». Industrial Management \& Data Systems, vol. 10, nº 8, pp. 400-406.

CHUNG, K.H. y SHIN, J.I. (2010): «The antecedents and consequents of relationship quality in internet shopping». Asia Pacific Journal of Marketing and Logistics, vol. $22, \mathrm{n}^{\circ} 4, \mathrm{pp} .473-491$.

CONSTANTINIDES, E. (2004): «Influencing the online consumer's behavior: the Web experience». Internet Research, vol. 14, n 2, pp. 111-126. 
CONSTANTINIDES, E. y FOUNTAIN, S.J. (2008): «Web 2.0: Conceptual foundations and marketing issues». Journal of direct, data and digital marketing practice, vol. 9, $\mathrm{n}^{\mathrm{o}} 3$, pp. 231-244.

CONSTANTINIDES, S. (2003): «The usefulness of ERP systems for effective management». Industrial Management \& Data Systems, vol. 103, nº 9, pp. 677-685.

CORRITORE, C.L., KRACHER, B. y WIEDENBECK, S. (2003): «On-line trust: concepts, evolving themes, a model». International Journal of Human-Computer Studies, vol. $58, \mathrm{n}^{\mathrm{o}} 6$, pp.737-758.

COX, J. y DALE, B.G. (2001): «Service quality and e-commerce: an exploratory analysis». Managing Service Quality: An International Journal, vol. 11, n 2, pp. 121-131.

CRISTÓBAL, E., FLAVIÁN, C. y GUINALIU, M. (2007): «e-service quality (PeSQ) Measurement validation and effects on consumer satisfaction and web site loyalty». Managing Service Quality: An International Journal, vol. 17, $\mathrm{n}^{\circ}$ 3, pp. 317-340.

DAI, H. y SALAM, A.F. (2010): «An Integrative Framework of Service Convenience, Service Consumption Experience, and Relational Exchange in Electronic Mediated Environment» (EME). In ICIS (p. 185).

DENG, Y., WU, Y., QIAN, Y., OUYANG, X., YANG, D. y QIU, X. (2010): «Adsorption and desorption behaviors of lignosulfonate during the self-assembly of multilayers». BioResources, vol. 5, no 2, pp. 1.178-1.196.

EGAN, J. (2011): Relationship Marketing. Harlow.

EGAN, J. (2012): Relationship Marketing. Harlow.

EGAN, R.J., BERGNER, C.L., HART, P.C., CACHAT, J.M., CANAVELLO, P.R., ELEGANTE, M.F. y MOHNOT, S. (2009): «Understanding behavioral and physiological phenotypes of stress and anxiety in zebrafish». Behavioural Brain Research, vol. 205, $\mathrm{n}^{\circ} 1, \mathrm{pp} .38-44$.

FASSNACHT, M. y KOESE, I. (2006): «Quality of electronic services: Conceptualizing and testing a hierarchical model». Journal of Service Research, vol. 9, n 1, pp. 19-37.

FEHR, B. (1988): «Prototype analysis of the concepts of love and commitment». Journal of Personality and Social Psychology, vol. 55, n ${ }^{\circ} 4$, pp. 557.

FORNELL, C. (1992): «A national customer satisfaction barometer: The Swedish experience». Journal of Marketing, vol. 56, $\mathrm{n}^{\circ}$ 1, pp. 6-21.

FULLERTON, G. (2003): «When does commitment lead to loyalty?» Journal of Service Research, vol. 5, no 4, pp. 333-344.

FULLERTON, G. (2005): «How commitment both enables and undermines marketing relationships». European Journal of Marketing, vol. 39, n 11/12, pp. 1.372-1.388.

GARBARINO, E. y JOHNSON, M.S. (1999): «The different roles of satisfaction, trust, and commitment in customer relationships». Journal of Marketing, vol. 63, $\mathrm{n}^{\mathrm{o}} 2$, pp.70-87.

GEFEN, D., KARAHANNA, E. y STRAUB, D.W. (2003): «Trust and TAM in online shopping: An integrated model». MIS quarterly, vol. 27, nº 1, pp. 51-90.

GRÖNROOS, C. (2000): «Relationship marketing: interaction, dialoge and value». Revista Europea de Dirección y Economía de la Empresa, vol. 9, n 3, pp. 13-24. 
GRÖNROOS, C. (2015): «Consumer dominant value creation: A theoretical response to the recent call for a consumer dominant logic for marketing». European Journal of Marketing, vol. 49, no 3/4, pp. 532-560.

GRUEN, T.W., SUMMERS, J.O. y ACITO, F. (2000): «Relationship marketing activities, commitment, and membership behaviors in professional associations». Journal of Marketing, vol. 64, n 3, pp. 34-49.

GUMMESSON, E. (1987): «The new marketing - developing long-term interactive relationships». Long range planning, vol. 20, n 4, pp. 10-20.

GUMMESSON, E. (2002): «Relationship marketing and a new economy: it's time for de-programming». Journal of Services Marketing, vol. 16, $\mathrm{n}^{\circ}$ 7, pp. 585-589.

GUNDLACH, G.T., ACHROL, R.S. y MENTZER, J.T. (1995): «The structure of commitment in exchange». The Journal of Marketing, pp. 78-92.

HA, HONG-YOUL (2004): «Factors influencing consumer perceptions of brand trust online». Journal of Product \& Brand Management, vol. 13, n 5, pp. 329-342.

HAIR, J.F., BUSH, R.P. y ORTINAU, D.J. (2010): Investigación de mercados. McGrawHill.

HARRISON-WALKER, L.J. (2001): «The measurement of word-of-mouth communication and an investigation of service quality and customer commitment as potential antecedents». Journal of service research, vol. 4, $\mathrm{n}^{\circ}$ 1, pp. 60-75.

HELLIER, P.K., GEURSEN, G.M., CARR, R.A. y RICKARD, J.A. (2003): «Customer repurchase intention: A general structural equation model». European Journal of Marketing, vol. 37, $\mathrm{n}^{\circ} 11 / 12$, pp. 1.762-1.800.

HERINGTON, C. y WEAVEN, S. (2009): «E-retailing by banks: e-service quality and its importance to customer satisfaction». European Journal of Marketing, vol. 43, $\mathrm{n}^{\circ}$ 9/10, pp. 1.220-1.231.

HESS, J. y STORY, J. (2005): Trust-based commitment: multidimensional consumerbrand relationships. Journal of Consumer Marketing, vol. 22, nº 6, pp. 313-322.

HO, C.I. y LEE, Y.L. (2007): «The development of an e-travel service quality scale». Tourism Management, vol.28, $\mathrm{n}^{\circ}$ 6, pp. 1.434-1.449.

HWANG, Y. y KIM, D.J. (2007): «Customer self-service systems: The effects of perceived Web quality with service contents on enjoyment, anxiety, and e-trust». Decision Support Systems, vol. 43, no 3, pp. 746-760.

KARJALUOTO, H., JAYAWARDHENA, C., LEPPÄNIEMI, M. y PIHLSTRÖM, M. (2012): «How value and trust influence loyalty in wireless telecommunications industry». Telecommunications Policy, vol. 36, nº 8, pp. 636-649.

KIM, A. J. y KO, E. (2012): «Do social media marketing activities enhance customer equity? An empirical study of luxury fashion brand». Journal of Business Research, vol. $65, \mathrm{n}^{\circ} 10$, pp. 1.480-1.486.

KIM, H. y FESENMAIER, D. R. (2008): «Persuasive design of destination web sites: An analysis of first impression». Journal of Travel Research, vol. 47, $\mathrm{n}^{\circ}$ 1, pp. 3-13.

KOTLER, P. y AMSTRONG, G. (2013): Fundamentos de Marketing (Decima primera Edición).(G. Dominguez Chávez, Ed.) Naucalpan de Juárez. 
LI, S., RAGU-NATHAN, B., RAGU-NATHAN, T.S. y RAO, S.S. (2006): «The impact of supply chain management practices on competitive advantage and organizational performance». Omega, vol. 34, n 2, pp. 107-124.

LIAO, C., PALVIA, P. y CHEN, J.L. (2009): «Information technology adoption behavior life cycle: Toward a Technology Continuance Theory (TCT)». International Journal of Information Management, vol. 29, n 4, pp. 309-320.

LIN, H.H. y WANG, Y.S. (2006): «An examination of the determinants of customer loyalty in mobile commerce contexts». Information \& Management, vol.43, $\mathrm{n}^{\circ} 3, \mathrm{pp}$. 271-282.

LIU, C. y ARNETT, K.P. (2000): «Exploring the factors associated with Web site success in the context of electronic commerce». Information \& Management, vol. 38, $\mathrm{n}^{\circ} 1, \mathrm{pp}$. 23-33.

LIU, Y., LI, Y., TAO, L. y WANG, Y. (2008): «Relationship stability, trust and relational risk in marketing channels: Evidence from China». Industrial Marketing Management, vol. 37, no 4, pp. 432-446.

LOIACONO, E.T., WATSON, R.T. y GOODHUE, D.L. (2002): «WebQual: A measure of website quality». Marketing theory and applications, vol.13, $\mathrm{n}^{\circ} 3$, pp. 432-438.

MCKNIGHT, D. H., CHOUDHURY, V. y KACMAR, C. (2002): «Developing and validating trust measures for e-commerce: An integrative typology». Information Systems Research, vol.13, n 3, pp. 334-359.

MOORMAN, C., ZALTMAN, G., y DESHPANDE, R. (1992). «Relationships between providers and users of market research: The dynamics of trust within and between organizations». Journal of Marketing Research, vol. 29, n ${ }^{\circ} 3$, pp. 314-328.

MOREIRA, A. C., y SILVA, P.M. (2015): «The trust-commitment challenge in service quality-loyalty relationships». International Journal of Health Care Quality Assurance, vol. 28, n $\mathrm{n}^{\mathrm{O}} 3$, pp. 253-266.

MOREIRA, A., SILVA, P.M., y MOUTINHO V.M. (2017): «The Effects of Brand Experiences on Quality, Satisfaction and Loyalty: An Empirical Study in the Telecommunications Multiple-play Service Market». Innovar, vol. 27, n 64, pp. 23-38.

MORGAN, R.M. y HUNT, S. (1999): «Relationship-based competitive advantage: the role of relationship marketing in marketing strategy». Journal of Business Research, vol. 46, no 3, pp. 281-290.

MORGAN, R.M., y HUNT, S.D. (1994): The commitment-trust theory of relationship marketing. The journal of Marketing, vol. 58, $\mathrm{n}^{\mathrm{o}} 3$, pp. 20-38.

MUKHERJEE, A., y NATH, P. (2007): «Role of electronic trust in online retailing: A reexamination of the commitment-trust theory». European Journal of Marketing, vol. 41, n ${ }^{\circ}$ 9/10, pp. 1.173-1.202.

NYSVEEN, H., PEDERSEN, P.E., y SKARD, S. (2013): «Brand experiences in service organizations: Exploring the individual effects of brand experience dimensions». Journal of Brand Management, vol. 20, $\mathrm{n}^{\circ}$ 5, pp. 404-423.

O'REILLY, C.A., y CHATMAN, J. (1986): «Organizational commitment and psychological attachment: The effects of compliance, identification, and internalization on prosocial behavior». Journal of Applied Psychology, vol. 71, n 3, pp. 492. 
OLIVER, R. L. (1999): Whence consumer loyalty? Journal of Marketing, vol. 63, $\mathrm{n}^{\circ} 4$, pp. 33-44.

PAIVA, G., SANDOVAL, M., y BERNARDIN, M. (2012): «Factores explicativos de la lealtad de clientes de los supermercados». Innovar, vol. 22, n 44, pp. 153-164.

PALMATIER, R.W., DANT, R.P., GREWAL, D., y EVANS, K.R. (2006): «Factors influencing the effectiveness of relationship marketing: a meta-analysis». Journal of Marketing, vol.70, $\mathrm{n}^{\circ}$ 4, pp. 136-153.

PARASURAMAN, A., ZEITHAML, V.A., y BERRY, L.L. (1988): "Servqual: A multipleitem scale for measuring consumer perc". Journal of Retailing, vol. 64, n 1, p.12.

PARASURAMAN, A., ZEITHAML, V.A., y MALHOTRA, A. (2005): «ES-QUAL: A multiple-item scale for assessing electronic service quality». Journal of Service Research, vol. 7, n⿳3 3, pp. 213-233.

PARK, Y. A. y GRETZEL, U. (2007): «Success factors for destination marketing web sites: A qualitative meta-analysis». Journal of Travel Research, vol. 46, n 1, pp. 46-63.

PARVATIYAR, A., y SHETH, J. N. (2001): «Customer relationship management: Emerging practice, process, and discipline». Journal of Economic \& Social Research, vol. 3, $\mathrm{n}^{\circ} 2$.

PORTER, L.W., STEERS, R.M., MOWDAY, R.T. y BOULIAN, P.V. (1974): «Organizational commitment, job satisfaction, and turnover among psychiatric technicians». Journal of Applied Psychology, vol. 59, n 5, p. 603.

PRADO ROMÁN, A., GONZÁLEZ, A.B. y IDOETA, C.M. (2014): «Análisis del proceso de generación de lealtad en el entorno on-line a través de la calidad del servicio y de la calidad de la relación». Revista Europea de Dirección y Economía de la Empresa, vol. 23, n 4, pp. 175-183.

RAMASESHAN, B., BEJOU, D., JAIN, S.C., MASON, C. y PANCRAS, J. (2006): «Issues and perspectives in global customer relationship management». Journal of Service Research, vol. 9, n 2, pp. 195-207.

RANAWEERA, C. y PRABHU, J. (2003): «The influence of satisfaction, trust and switching barriers on customer retention in a continuous purchasing setting». International Journal of Service Industry Management, vol. 14, $\mathrm{n}^{\circ}$ 4, pp. 374-395.

RAUYRUEN, P. y MILLER, K. E. (2007): «Relationship quality as a predictor of B2B customer loyalty». Journal of Business Research, vol. 60, $\mathrm{n}^{\circ}$ 1, pp. 21-31.

ROBERTS, K., VARKI, S. y BRODIE, R. (2003). «Measuring the quality of relationships in consumer services: an empirical study». European Journal of Marketing, vol. 37, $\mathrm{n}^{\mathrm{o}} 1 / 2$, pp. 169-196.

SAHADEV, S. y PURANI, K. (2008): «Modelling the consequences of e-service quality . Marketing Intelligence \& Planning, vol. 26, $\mathrm{n}^{\circ}$ 6, pp. 605-620.

SARMIENTO GUEDE, J.R. (2014): Marketing de relaciones en los medios sociales: Estudio empírico de los antecedentes y consecuentes de la calidad de la relación en los sitios web de viajes (Doctoral dissertation, Universidad Rey Juan Carlos).

SARMIENTO GUEDE, J.R. (2015): «La comunicación de 'boca en boca'vs. la de 'boca en boca electrónica’: Análisis de sus principales diferencias». Ámbitos, vol. 30, pp. 1-17.

SARMIENTO GUEDE, J.R. (2017): «La experiencia de la calidad de servicio online como antecedente de la satisfacción online: estudio empírico en los sitios web de viajes». Investigaciones Turísticas, vol.13, pp. 30-53. 
SARMIENTO GUEDE, J.R. (2017): «Los medios sociales a través de la experiencia web: un análisis de su percepción desde un enfoque relacional». Aposta, vol. 73, pp. 30-59.

SARMIENTO GUEDE, J.R. (2017): «Marketing de relaciones: un análisis del contenido de sus fundamentos teóricos». Anuario Jurídico y Económico Escurialense, vol. 50, pp. 279-400.

SARMIENTO GUEDE, J.R. (2018): «La fidelización como consecuente de la calidad de la relación en las organizaciones». Anuario Jurídico y Económico Escurialense, vol.51, pp. 337-354.

SARMIENTO GUEDE, J.R., DE ESTEBAN CURIEL, J. y ANTONOVICA, A. (2017): «La comunicación viral a través de los medios sociales: análisis de sus antecedentes». Revista Latina de Comunicación Social, vol. 72, p. 69-86.

SARMIENTO GUEDE, J.R. (2015): Marketing de Relaciones. Aproximación a las relaciones virtuales. Dykinson. Madrid.

SCHLESINGER, W., CERVERA, A. y CALDERÓN, H. (2014): «El papel de la confianza, la imagen y los valores compartidos en la creación de valor y lealtad: aplicación a la relación egresado-universidad». Revista Española de Investigación en Marketing ESIC, vol. 18, n 2, pp.126-139.

SIRDESHMUKH, D., SINGH, J. y SABOL, B. (2002): «Consumer trust, value, and loyalty in relational exchanges». Journal of Marketing, vol. 66, $\mathrm{n}^{\circ} 1$, pp. 15-37.

SOLOMON, M., RUSSELL-BENNETT, R. y PREVITE, J. (2012): Consumer behaviour. Pearson Higher Education AU.

STORBACKA, K., STRANDVIK, T. y GRÖNROOS, C. (1994): «Managing customer relationships for profit: the dynamics of relationship quality». International Journal of Service industry management, vol. 5, $\mathrm{n}^{\circ}$ 5, pp. 21-38.

SUGIMOTO, C. R., WORK, S., LARIVIÈRE, V. y HAUSTEIN, S. (2017): «Scholarly use of social media and altmetrics: A review of the literature». Journal of the Association for Information Science and Technology, vol. 68, $\mathrm{n}^{\circ}$ 9, pp. 2.037-2.062.

SZYMANSKI, D. M. y HISE, R. T. (2000): «E-satisfaction: an initial examination». Journal of retailing, vol. 76, $\mathrm{n}^{\circ} 3$, pp. 309-322.

TOFFLER, A. y ALVIN, T. (1981): The third wave (pp. 32-33). New York: Bantam books.

TORTOSA, V., MOLINER, M.A. y SÁNCHEZ, J. (2009): «Internal market orientation and its influence on organisational performance». European Journal of Marketing, vol. 43, n ${ }^{\circ} 11 / 12$, pp.1.435-1.456.

ULAGA, W. y EGGERT, A. (2006): «Relationship value and relationship quality: Broadening the nomological network of business-to-business relationships». European Journal of Marketing, vol.40, n $\mathrm{n}^{\mathrm{O}}$ 3/4, pp. 311-327.

VON DER HEIDT, T. y LAMBERTON, G. (2011): «Sustainability in the undergraduate and postgraduate business curriculum of a regional university: A critical perspective». Journal of Management \& Organization, vol. 17, $\mathrm{n}^{\circ}$ 5, pp. 670-690.

WOLFINBARGER, M. y GILLY, M.C. (2001): «Shopping online for freedom, control, and fun». California Management Review, vol. 43, n 2, pp. 34-55.

WU, C. S., LIN, C.T. y LEE, C. (2010): «Optimal marketing strategy: A decision-making with ANP and TOPSIS». International Journal of Production Economics, vol. 127, $\mathrm{n}^{\circ}$ 1, pp.190-196. 
YOO, B. y DONTHU, N. (2001): «Developing and validating a multidimensional consumer-based brand equity scale». Journal of Business Research, vol. 52, n 1, pp. 1-14.

ZARANTONELLO, L. y SCHMITT, B.H. (2010): «Using the brand experience scale to profile consumers and predict consumer behaviour». Journal of Brand Management, vol. $17, \mathrm{n}^{\mathrm{o}} 7$, pp. 532-540.

ZEITHAML, V.A. (2000): «Service quality, profitability, and the economic worth of customers: what we know and what we need to learn». Journal of The Academy of Marketing Science, vol. 28, $\mathrm{n}^{\circ} 1$, pp. 67-85.

ZEITHAML, V.A., LEMON, K.N. y RUST, R.T. (2001): Driving customer equity: How customer lifetime value is reshaping corporate strategy. Simon and Schuster. 